\title{
EXPERIMENTAL EVIDENCE THAT BOTH PARTIES BENEFIT IN A FACULTATIVE PLANT-SPIDER MUTUALISM
}

\author{
KENNETH D. WhitNEY ${ }^{1}$ \\ Center for Population Biology and Section of Evolution and Ecology, University of California, One Shields Avenue, \\ Davis, California 95616 USA
}

\begin{abstract}
Spiders are known to influence plant fitness, and vice versa. Yet, it has not been appreciated that these facultative relationships can be mutualistic. I examined the interaction between Phryganoporus candidus, a subsocial Australian spider, and the extrafloral nectary-bearing shrub Acacia ligulata to explore variability in mutualistic interactions over a three-year period. Spiders enhanced seed production by reducing seed predation by heteropterans, wasps, and weevils. Because spider colonies occupy only a fraction of a plant's volume, average benefits ranged from 0.4 to $6 \%$ increases in whole-plant seed production. These benefits were strongest in years of low seed production, suggesting that spiders may buffer plants against female reproductive failure. To evaluate benefits for spiders, I established experimental spider colonies on three common hosts. Spider performance (persistence and prey capture rates) on live A. ligulata and live hopbush Dodonaea viscosa exceeded that on dead acacia, suggesting that live hosts are more beneficial than dead hosts. Stable-isotope analyses demonstrated that colonies living on the three hosts differed substantially in diet, providing a possible mechanism for the observed differential suitability of hosts. However, the analyses were unable to establish conclusively that $A$. ligulata extrafloral nectar was an important reward for spiders. Variability in the A. ligulata$P$. candidus system suggests that plant-spider associations, like other facultative protection relationships, likely vary along a continuum from antagonism to mutualism.
\end{abstract}

Key words: Acacia; density-mediated indirect effects; extrafloral nectar; Kinchega National Park, New South Wales, Australia; mutualism; Phryganoporus candidus; plant-spider interactions; seed predation, predispersal; spiders; stable isotope analysis; top-down effects; trophic cascade.

\section{INTRODUCTION}

Studies examining plant-spider interactions have followed two separate paths, with limited integration. The top-down vs. bottom-up debate in food-web ecology has lead to studies that either observe or manipulate spider abundances and examine indirect effects on plants (reviewed in Schmitz et al. [2000] and Halaj and Wise [2001]). These studies demonstrate that spiders can have positive effects on plants via local suppression of herbivores (e.g., Polis and Hurd 1996, Denno et al. 2002), but also can have no effects (e.g., Spiller and Schoener 1994) or negative effects (e.g., Ott et al. 1998, Gastreich 1999). A separate set of studies have shown that plants can benefit spiders. Direct benefits include both pollen and nectar; the latter in particular can increase spider survival (Vogelei and Greissl 1989, Taylor and Foster 1996) and is ingested by many spider species (Taylor and Foster 1996, Ruhren and Handel 1999, Jackson et al. 2001). Plants can indirectly benefit spiders by providing substrates for web building and hunting (Wise 1993), attracting insect prey (Morse

Manuscript received 28 April 2003; revised 7 October 2003; accepted 9 October 2003. Corresponding Editor: O. J. Schmitz.

${ }^{1}$ Present address: Department of Biology, Jordan Hall 142, Indiana University, Bloomington, Indiana 47405-3700 USA. E-mail:kdwhitne@indiana.edu
1999, Schmalhofer 2001), and offering suitable microclimates (Riechert and Tracy 1975).

The potential for positive, reciprocal relationships between plants and spiders thus appears large, but such reciprocity has not yet been documented. Here I present an examination of plant-spider interactions in a mutualistic context. I define mutualism as a $+/+$ interaction that can span a range of intensity (from weak to strong, from facultative to obligate) and that may or may not be coevolved (Bronstein 1994). I examined the Australian shrub Acacia ligulata and the subsocial spider Phryganoporus candidus, which nests on the plant. I asked whether the relationship can be mutually beneficial, whether benefits vary in space or time, and what mechanisms might underlie the benefits provided.

\section{Methods \\ Study system}

Acacia ligulata is widespread in arid and semi-arid Australia (Maslin and Hopper 1982), reaching $5 \mathrm{~m}$ in height. This species produces zero to several (usually one) extrafloral nectaries along the margin of each phyllode (leaf analogue). In Kinchega National Park, New South Wales, plants flower in September, fruits develop over a two-month period, and fruit dehiscence and seed dispersal follow from mid-December through February. Immature fruits are attacked by insect seed 


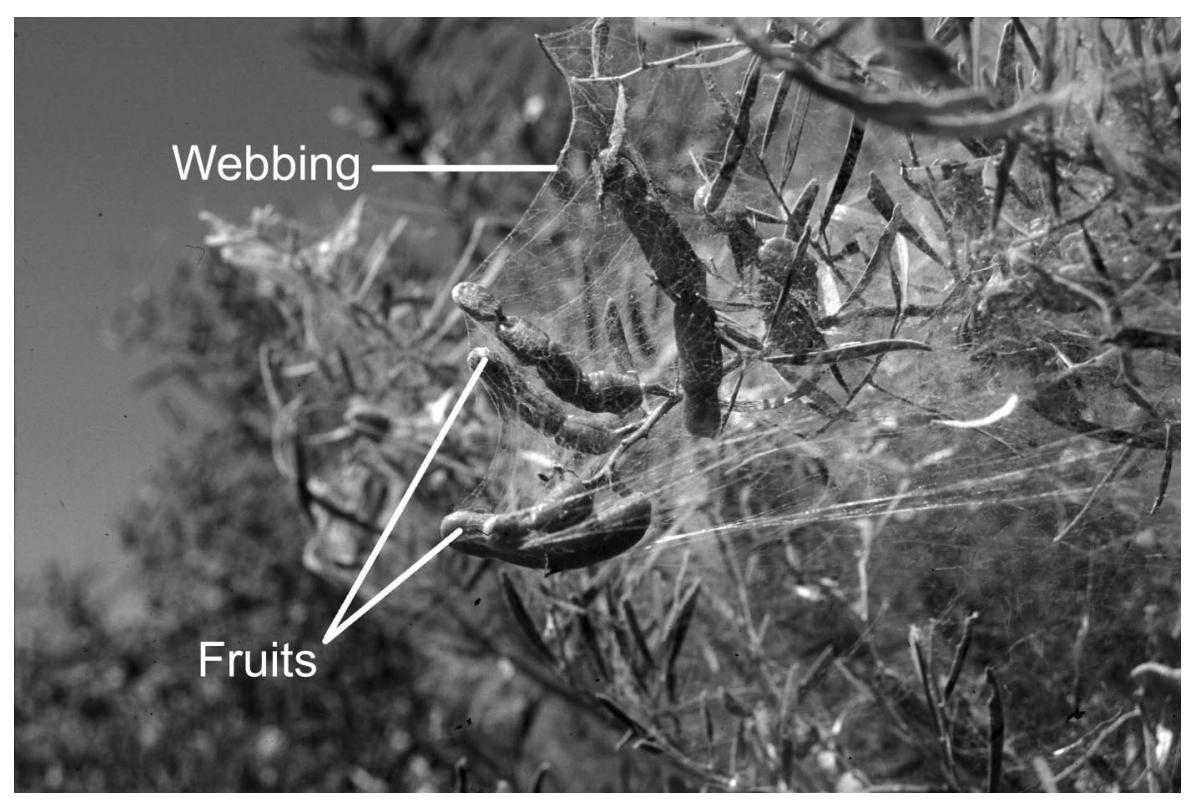

Plate. 1. Immature fruits of Acacia ligulata enmeshed within prey capture webbing of the spider Phyrganoporus candidus. Photo credit: Ken Whitney.

predators including Coleotichus costatus (Heteroptera), Alydidae spp. (Heteroptera), the wasp Trichologaster sp. (Chalcidae), and Melanterius weevils (Cucurlionidae) (Whitney and Stanton 2004). Seeds are dispersed by ants and birds (Whitney 2002).

Phryganoporus candidus is a subsocial spider that occurs in continental Australia and Tasmania (Gray 2002). A single gravid female establishes a colony; she and her offspring collectively build a nest that houses the juveniles until maturity (Downes 1993). Nests are comprised of a dense central chambered area (the retreat) and peripheral prey-capture webbing on branches, leaves, and fruits of the host plant (Downes 1994; personal observation). In Kinchega National Park, $P$. candidus colonies occur on eight species of live shrubs and trees as well as on standing dead individuals (personal observation).

The interaction between $P$. candidus and A. ligulata was explored in two A. ligulata populations separated by $20.5 \mathrm{~km}$ within Kinchega National Park: Menindee $\left(32^{\circ} 23^{\prime} \mathrm{S}, 142^{\circ} 24^{\prime} \mathrm{E}\right)$ and Cawndilla $\left(32^{\circ} 27^{\prime} \mathrm{S}, 142^{\circ} 11^{\prime}\right.$ E). I made observations on naturally occurring colonized plants in both sites, but performed experiments at Menindee only. In Kinchega, spider colonies establish in late September, coincident with the end of the A. ligulata flowering period. Across three years and two sites, on average $32 \% \pm 3.9 \%$ A. ligulata plants (mean $\pm 1 \mathrm{SE}$ ) were colonized, with a mean of $2.6 \pm$ 0.24 nests per colonized plant. By November, preycapture webbing encompasses immature fruits (see Plate 1) in $64 \%$ of nests, reflecting the patchy distribution of fruit within plants. At this time, average nest volume is $0.02 \pm 0.005 \mathrm{~m}^{3}$, while the average volume of suitable spider substrate on a plant (encompassing green stems, phyllodes, and fruits) is $8.1 \pm 0.50 \mathrm{~m}^{3}$ (mean $\pm 1 \mathrm{SE}$ ). Nest web volume peaks in December as the juvenile spiders mature and begin to emigrate. Subsequent web degradation allows dispersal of most seeds during the normal dispersal season (personal observation).

\section{Benefits to plants}

Naturally colonized plants.-I assessed the effects of spiders on A. ligulata seed production in naturally colonized plants in two sites over three years (19992001). In each year, I randomly chose 7-34 plants at each site from among those supporting spider colonies. Sample sizes reflected natural variability in spider-colony abundance. In late December, I collected $\geq 10$ fruits from inside naturally occurring $P$. candidus colonies on each plant and compared them to $\geq 10$ fruits collected from outside the colonies on the same plant.

Experimentally colonized plants.-I established experimental colonies at Menindee in mid-October 2000 and 2001 to determine whether spiders cause (or are simply correlated with) decreases in seed predation. In each year, I randomly chose 21 A. ligulata plants. I flagged two areas of high immature-fruit density on each plant, and randomly assigned them to a spider treatment (colony or control). Areas in the colony treatment received a $P$. candidus colony (retreat area only) on a branch cut from a nearby A. ligulata host and attached with twist ties. The control treatment received a bare branch cut from the same host. Spiders in transferred colonies constructed new prey-capture webbing within a few days. All colonies eventually included fruits within their webbing. In late December of each 
year I collected $\geq 10$ mature fruits at random from the colony and control areas on each plant.

Response variables.-I processed fruits collected from the naturally and experimentally colonized plants identically, as follows. Fruits within a treatment on a given plant were pooled. The total number of initiated ovules was estimated by the number of chambers in the woody pods. The total numbers of viable, heteropteran-killed, wasp-killed, and weevil-killed seeds were tallied; each of the seed predators leave characteristic signs of damage (Whitney and Stanton 2004). Response variables were formed by dividing the numbers of seeds in each of the four seed-fate categories by the number of ovules, and were angular transformed prior to analysis.

Statistical analysis.-I did not score heteropteran damage in natural colonies during 1999, and wasps did not occur at the Cawndilla site, precluding multivariate analysis. Therefore, I performed separate ANOVAs (SAS Institute 2000) for each response variable, and adjusted $P$ values using the conservative Bonferroni criterion for $k=4$ tests. Site, year, and plant (nested within site and year) were analyzed as random factors, while spider presence was considered fixed. Because of the nested experimental design, I used the variation among plants as the error term for testing the effects of site, year, and their interaction. For plants with experimental spider colonies, the effects of plant (nested within year) and year (both random effects) as well as spider treatment (fixed) on the fractions of seeds in all four categories were analyzed first by MANOVA, and then by protected ANOVA (Scheiner 2001, SAS Institute 2000). Because residuals in initial parametric analyses were not always normally distributed, I analyzed both the natural and experimental results nonparametrically via ANOVA on the ranked data (Conover and Iman 1981).

Benefits to whole-plant reproduction.-I related changes in the fractional survival of seeds (as investigated above) to plant fecundity by estimating total seed production per plant. Because spider colonies are small relative to plants, only a fraction of fruits are enclosed within nests. Spiders can influence the number of viable seeds matured per ovule for these fruits. In each site and year, total ovule production for $>30$ randomly chosen plants was estimated by measuring three multiplicative components: canopy surface area (in square meters), number of fruits per square meter, and number of ovules per fruit (Whitney and Stanton 2004). I estimated whole-plant seed production in the absence of spiders (base number of seeds, $S_{\mathrm{b}}$ ) by assigning the value of viable seeds/ovule measured outside colonies to all ovules on the plant (regardless of whether they occurred inside or outside colonies). I then considered $\geq 10$ plants/site that had been naturally colonized by spiders. I estimated the number of additional seeds reaching maturity due to the presence of spiders $\left(S_{\mathrm{s}}\right)$ by multiplying (viable seeds/ovule inside colony - vi- able seeds/ovule outside colony) by the total number of ovules contained in colonies. I then calculated the mean percentage change in seed production for plants colonized by spiders relative to those uncolonized (the "benefit") as $100 \times\left(\left[S_{\mathrm{b}}+S_{\mathrm{s}}\right] / S_{\mathrm{b}}\right)-100$.

\section{Benefits to spiders}

Spider utilization of alternative hosts.-In November 2001 I compared the abundance and vigor of $P$. candidus colonies on three common plant hosts: live A. ligulata, live hopbush Dodonaea viscosa ssp. angustissima, and dead acacias (A. ligulata, A. victoriae). These hosts are roughly equal in size, but only A. ligulata has extrafloral nectaries. I tallied the number of $P$. candidus colonies and measured nest volumes (length $\times$ width $\times$ height) on each host. Nest volume correlates well with spiderling number and thus with female fitness (Downes 1994). I examined site (random) and host-plant type (fixed) effects on colony number and volume using ANOVA (SAS Institute 2000). ANOVAs on ranked data were performed because residuals in parametric analyses were non-normal (Conover and Iman 1981). Colonies were relatively rare on dead acacias ( $n=4$ and $n=3$ for Menindee and Cawndilla, respectively) vs. on live A. ligulata $(n=61$ and 17 ), and on hopbush ( $n=20$ and 26); thus the analysis of colony volume was restricted to live A. ligulata and hopbush.

Spider performance on alternative hosts.-To determine whether $P$. candidus colonies perform better on live A. ligulata vs. alternative hosts, I established subcolonies of juvenile spiders in the field at Menindee, and measured colony persistence (the fraction of spiders still present after $10 \mathrm{~d}$ ) and prey-capture rates. I created 15 blocks, each consisting of a dead acacia, the nearest live A. ligulata, and the nearest live hopbush. On 5 November 2001 I harvested two large $P$. candidus colonies ("parental colonies") from A. ligulata and divided them into 45 subcolonies of 15 juveniles each. Subcolonies were allowed to establish for $40 \mathrm{~h}$ in the laboratory in 60-mL plastic cups. Each subcolony was then wired onto a host at a height of $\sim 1.5 \mathrm{~m}$. All subcolonies within a block were derived from the same parental colony. I measured the volume of prey-capture webbing $(\mathrm{L} \times \mathrm{W} \times \mathrm{H})$ and prey-capture rates (number of prey per cubic centimeter of webbing) $10 \mathrm{~d}$ after placement. Subcolonies were removed and the numbers of remaining $P$. candidus juveniles were counted in the laboratory. Using MANOVA and protected ANOVA, I tested the effects of block and host on colony persistence (which reflects both mortality and emigration) and prey-capture rates.

Spider diet on alternative hosts: stable-isotope analyses.-Different host plants may influence the diets of resident spiders by providing nectar sources (or not), and by attracting different assemblages of insect herbivores, predators, and parasitoids. I employed stableisotope analyses of carbon $\left({ }^{13} \mathrm{C}:{ }^{12} \mathrm{C}\right)$ and nitrogen 
$\left({ }^{15} \mathrm{~N}:{ }^{14} \mathrm{~N}\right)$ to evaluate host-plant effects on spider diets. Background on stable-isotope techniques and detailed sampling methods are given in Appendix A. I calculated the contributions of insect prey and nectar to spider diet, and determined $95 \%$ confidence intervals for these estimates, using a two-source mixing model (Phillips and Gregg 2001). I used a range of enrichment values (Post 2002) to investigate the sensitivity of the results to assumptions about trophic fractionation. To compare diets of $P$. candidus colonies living on different hosts, I measured $\delta^{15} \mathrm{~N}$ and $\delta^{13} \mathrm{C}$ values for spiders on live A. ligulata, hopbush, and dead acacias and examined host-plant effects using MANOVA (SAS Institute 2000).

\section{RESUlts \\ Benefits to plants}

Naturally occurring nests of Phryganoporus candidus were associated with 20-406\% increases in Acacia ligulata seed production per ovule, relative to adjacent control areas outside nests (Fig. 1A and B, Table 1). These nests were also associated with significant reductions in seed predation (Table 1; Appendix B): mean heteropteran seed damage inside nests was reduced by $52-85 \%$ relative to outside nests; wasp damage was reduced by $70-93 \%$. The spider effect on weevil damage varied in magnitude (Site $\times$ Year $\times$ Spider $P=$ 0.007 , Table 1) but was consistent in direction; mean weevil seed damage was reduced by $54-95 \%$. For a given site and year, the amount of reduction in seed damage in colonies corresponded roughly to the amount of increase in viable seed production (Fig. 1A and B; Appendix B).

These patterns were largely repeated when spider presence was experimentally manipulated (Fig. 1C; Appendix B). MANOVA indicated significant year (Pillai's trace $0.28, F_{4,38}=3.69, P=0.012$ ) and spider treatment effects (Pillai's trace 0.77, $F_{4,38}=32.02, P$ $<0.0001)$. Viable seed production per ovule inside experimental nests was $191-269 \%$ that outside nests (Fig. 1C), a significant increase (Table 1). The enhanced seed production inside nests was associated with significant reductions in seed damage by heteropterans and wasps (Table 1; Appendix B). Mean heteropteran seed damage inside nests was reduced by 63 $76 \%$ relative to outside nests; wasp damage was reduced by $22-77 \%$. Manipulation of spiders did not significantly reduce weevil damage $(P=0.426$, Table 1$)$.

I estimated that colonization by spiders increases whole-plant seed production modestly, from 0.38 to $5.77 \%$ depending on the site and year. Results for Menindee (where $S_{\mathrm{b}}=$ base number of seeds in absence of spiders and $S_{\mathrm{s}}=$ additional number of seeds reaching maturity due to presence of spiders; data are means \pm $1 \mathrm{SE})$ were as follows: $1999, S_{\mathrm{b}}=5358 \pm 1027$ seeds, $S_{\mathrm{s}}=20 \pm 8$ seeds, benefit $=+0.38 \% ; 2000, S_{\mathrm{b}}=869$ \pm 228 seeds, $S_{\mathrm{s}}=50 \pm 14$ seeds, benefit $=+5.77 \%$;
A) Cawndilla, naturally colonized plants

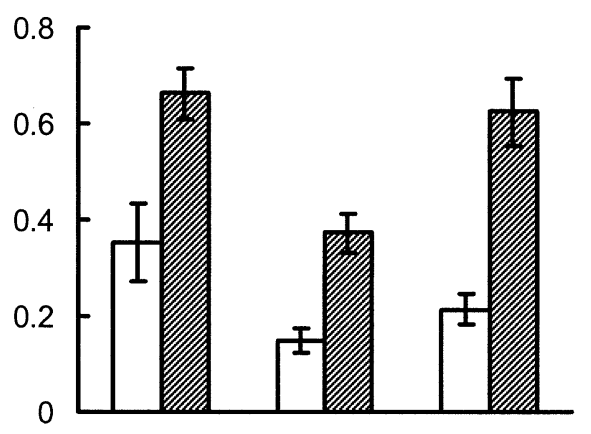

B) Menindee, naturally colonized plants
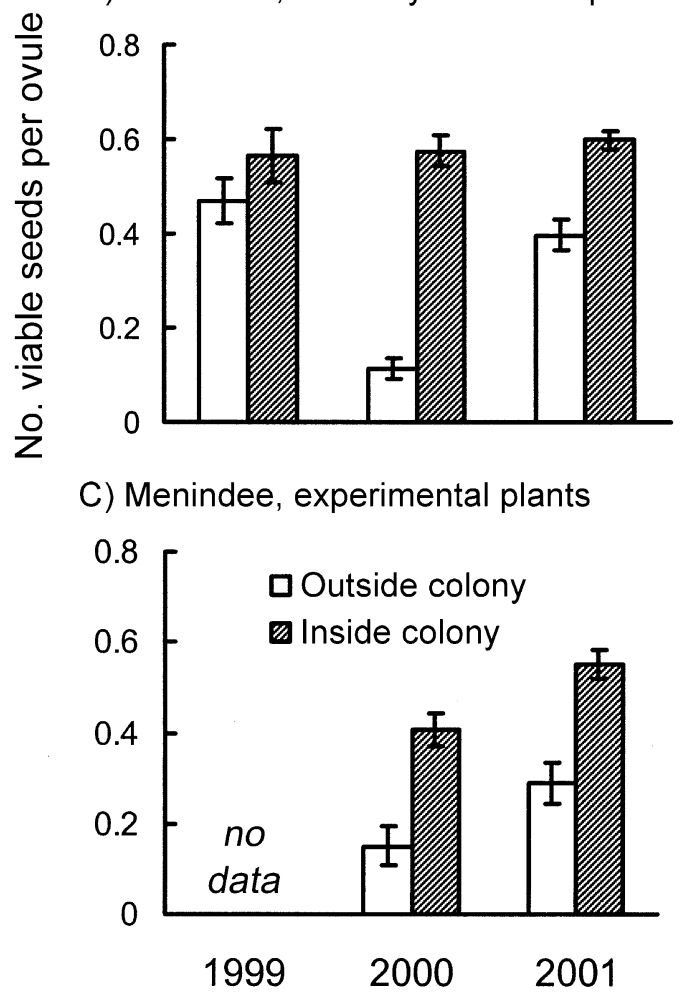

FIG. 1. Spider effects on the number of viable seeds per ovule in Acacia ligulata fruits at two sites in Kinchega National Park, New South Wales, Australia. Two spider treatments (outside vs. inside Phryganoporus candidus colonies) are shown. Data are means \pm 1 SE. (A) Naturally colonized plants at Cawndilla; $n=7,22$, and 11 plants for 1999, 2000, and 2001, respectively. (B) Naturally colonized plants at Menindee; $n=9,34,24$ plants. (C) Plants to which experimental spider colonies were attached at Menindee; $n=0$, 22, 21 plants.

$2001, S_{\mathrm{b}}=4066 \pm 565$ seeds, $S_{\mathrm{s}}=17 \pm 6$ seeds, benefit $=+0.41 \%$. Results for Cawndilla were: 1999, $S_{\mathrm{b}}=1143 \pm 261$ seeds, $S_{\mathrm{s}}=7 \pm 3$ seeds, benefit $=$ $+0.58 \% ; 2000, S_{\mathrm{b}}=1203 \pm 277$ seeds, $S_{\mathrm{s}}=25 \pm 10$ seeds, benefit $=+2.10 \% ; 2001, S_{\mathrm{b}}=494 \pm 156$ seeds, $S_{\mathrm{s}}=12 \pm 5$ seeds, benefit $=+2.33 \%$. However, these average values hide a wide range of variability. For 
TABLE 1. Effects of site, year, and spider treatment on seed fate in Acacia ligulata plants with natural and experimental Phryganoporus candidus colonies.

\begin{tabular}{|c|c|c|c|c|c|c|}
\hline \multirow[b]{2}{*}{ Source of variation } & \multicolumn{3}{|c|}{ Viable seeds } & \multicolumn{3}{|c|}{ Heteropteran-killed seeds } \\
\hline & df & $F$ & $P$ & df & $F$ & $P$ \\
\hline \multicolumn{7}{|l|}{ Plants with natural colonies } \\
\hline Site & 1,102 & 5.27 & 0.0236 & 1,87 & 36.43 & $<\mathbf{0 . 0 0 0 1}$ \\
\hline Year & 2,102 & 28.14 & $<\mathbf{0 . 0 0 0 1}$ & 1,87 & 0.08 & 0.7803 \\
\hline Spider & 1,100 & 130.48 & $<\mathbf{0 . 0 0 0 1}$ & 1,87 & 102.74 & $<\mathbf{0 . 0 0 0 1}$ \\
\hline Site $\times$ Year & 2,100 & 0.99 & 0.3745 & 1,87 & 0.73 & 0.3940 \\
\hline Site $\times$ Spider & 1,100 & 0.36 & 0.5486 & 1,87 & 1.02 & 0.3147 \\
\hline Year $\times$ Spider & 2,100 & 1.55 & 0.2182 & 1,87 & 0.65 & 0.4227 \\
\hline Site $\times$ Year $\times$ Spider & 2,100 & 10.99 & $<\mathbf{0 . 0 0 0 1}$ & 1,87 & 2.41 & 0.1245 \\
\hline Plant (Site $\times$ Year) & 102,100 & 1.00 & 0.5027 & 87,87 & 1.10 & 0.3350 \\
\hline \multicolumn{7}{|c|}{ Plants with experimental colonies } \\
\hline Year & 1,41 & 10.06 & 0.0029 & 1,41 & 7.67 & 0.0084 \\
\hline Spider & 1,41 & 74.53 & $<\mathbf{0 . 0 0 0 1}$ & 1,41 & 59.58 & $<0.0001$ \\
\hline Year $\times$ Spider & 1,41 & 0.03 & 0.8589 & 1,41 & 0.46 & 0.5015 \\
\hline Plant (Year) & 41,41 & 2.48 & 0.0022 & 41,41 & 2.82 & 0.0006 \\
\hline
\end{tabular}

Notes: Fruits within a treatment on a given plant were pooled for analysis. Presented are ANOVAs of the ranked angulartransformed fraction of seeds viable, killed by heteropterans, killed by weevils, or killed by wasps. Tests significant after Bonferroni adjustment for $k=4$ tests are indicated in boldface. The Cawndilla site was excluded from the analysis of the fraction killed by wasps in plants with natural colonies, since wasps did not occur there.

example, in 2000 at Menindee, 10 of 36 naturally colonized plants produced viable seeds only inside of spider colonies; on these plants, all fruits outside of colonies failed to mature viable seeds. In the remaining plants, spiders were associated with increases in seed production ranging from $0.0 \%$ (on plants where no fruits matured within colonies) to $1269 \%$ (on a plant with several colonies encompassing many fruits).

\section{Benefits to spiders}

Spider utilization of alternative hosts.-The number and volume of $P$. candidus colonies varied markedly across hosts (number, $F_{2,271}=11.98, P<0.0001$; volume, $F_{1,120}=11.46, P=0.001$ ) and sites (number, $F_{1,271}=7.89, P=0.005$; volume, $F_{1,120}=150.21, P$ $<0.0001)$. For both variables, there was a highly significant site $\times$ host interaction (number, $F_{2,271}=11.81$, $P<0.0001$; volume, $\left.F_{1,120}=10.47, P=0.002\right)$. At Menindee, the number of colonies per plant was greater on A. ligulata $(0.73 \pm 0.17$ colonies [mean $\pm 1 \mathrm{SE}$ ], $n$ $=103$ plants $)$ than on either hopbush $(0.39 \pm 0.14$ colonies, $n=54$ plants $)$ or dead acacias $(0.13 \pm 0.06$ colonies, $n=30$ plants), although only the contrast with dead acacia was statistically significant ( $A$. ligulata vs. hopbush, $F_{1,271}=0.98, P=0.324 ;$ A. ligulata vs. dead acacia, $F_{1,271}=4.05, P=0.045$; hopbush vs. dead acacia, $\left.F_{1,271}=1.22, P=0.270\right)$. Nest volume was at least an order of magnitude larger on A. ligulata $\left(28642 \pm 6481.1 \mathrm{~cm}^{3}\right.$ [mean $\left.\pm 1 \mathrm{SE}\right] n=61$ nests $)$ than on either alternative host (hopbush, $2815 \pm 754.2$ $\mathrm{cm}^{3}, n=20$ nests; dead acacia, $369 \pm 264.1 \mathrm{~cm}^{3}, n=$ 4 nests). Nest volume on A. ligulata and hopbush differed significantly (contrast, $\mathrm{F}_{1,120}=27.01, P<$ $0.0001)$; contrasts of volume involving dead acacias were not performed because so few colonies occurred on them.
At Cawndilla the number of colonies per plant was much higher on hopbush $(5.14 \pm 2.53$ colonies [mean $\pm 1 \mathrm{SE}], n=21$ plants) than on either alternative host (A. ligulata, $0.38 \pm 0.11$ colonies, $n=48$ plants; dead acacia, $0.14 \pm 0.08$ colonies, $n=21$ plants); these differences were significant (contrast, $F_{1,271}=25.39$, $P<0.0001$, and $F_{1,271}=25.45, P<0.0001$, respectively). The mean number of colonies per plant did not differ between A. ligulata and dead acacia (contrast, $\left.F_{1,271}=0.83, P=0.363\right)$. Mean nest volume was much smaller than at Menindee (A. ligulata, $167 \pm 24.9 \mathrm{~cm}^{3}$, $n=17$ nests; hopbrush, $188 \pm 34.3 \mathrm{~cm}^{3}, n=26$ nests; dead acacia, $145 \pm 67.4 \mathrm{~cm}^{3}, n=3$ nests), and did not differ significantly between A. ligulata and hopbush (contrast, $F_{1,120}=0.01, P=0.923$ ).

Spider performance on alternative hosts.-Host identity (A. ligulata, hopbush, or dead acacia) had strong effects on the persistence of experimentally placed subcolonies and on their prey-capture rates (MANOVA; Pillai's trace 0.41, $F_{4,50}=3.23, P=$ $0.020)$. Little of the variation was explained by block (Pillai's trace $0.84, F_{28,50}=1.29, P=0.215$ ). Persistence was greatest on A. ligulata, followed by that on hopbush and dead acacia (Fig. 2A). Spider persistence on the two living hosts did not differ statistically (contrast, $F=0.06, P=0.80$ ), and persistence on them was significantly greater than on dead acacia $(A$. ligulata, $F=7.22, P=0.012$; hopbush, $F=5.92, P=$ 0.022). Prey-capture rates on the two living hosts were similar $(F=2.02, P=0.169$; Fig. $2 \mathrm{~B})$, and rates on hopbush were significantly greater than those on dead acacias $(F=7.75, P=0.011$; Fig. $2 \mathrm{~B})$. While prey capture rates on $A$. ligulata were more than twice those on dead acacias, this difference was not statistically significant $(F=2.73, P=0.112$; Fig. 2B). 
TABle 1. Extended.

\begin{tabular}{|c|c|c|c|c|c|}
\hline \multicolumn{3}{|c|}{ Weevil-killed seeds } & \multicolumn{3}{|c|}{ Wasp-killed seeds } \\
\hline df & $F$ & $P$ & $\mathrm{df}$ & $F$ & $P$ \\
\hline 1,102 & 5.97 & 0.0162 & $\ldots$ & $\ldots$ & $\ldots$ \\
\hline 2,102 & 1.81 & 0.1683 & 2,65 & 1.13 & 0.3284 \\
\hline 1,100 & 81.42 & $<\mathbf{0 . 0 0 0 1}$ & 1,63 & 37.59 & $<\mathbf{0 . 0 0 0 1}$ \\
\hline 2,102 & 2.76 & 0.0681 & $\ldots$ & $\ldots$ & $\ldots$ \\
\hline 1,100 & 0.71 & 0.4003 & $\ldots$ & $\ldots$ & $\ldots$ \\
\hline 2,100 & 1.27 & 0.2848 & 2,63 & 1.70 & 0.1913 \\
\hline 2,100 & 5.16 & 0.0074 & $\ldots$ & $\ldots$ & $\ldots$ \\
\hline 102,100 & 1.56 & 0.0135 & 65,63 & 1.46 & 0.0683 \\
\hline 1,41 & 4.25 & 0.0456 & 1,41 & 0.35 & 0.5556 \\
\hline 1,41 & 0.65 & 0.4259 & 1,41 & 10.04 & 0.0029 \\
\hline 1,41 & 0.30 & 0.5884 & 1,41 & 1.90 & 0.1757 \\
\hline 41,41 & 2.43 & 0.0027 & 41,41 & 1.49 & 0.1043 \\
\hline
\end{tabular}

Spider diet on alternative hosts: stable-isotope analyses.-Estimates of the relative dietary contributions of prey insects and A. ligulata extrafloral nectar to spiders varied widely, depending both on the element considered (carbon or nitrogen) and the assumptions made about trophic fractionation (Table 2). For average trophic fractionation values $\left(0.4 \%\right.$ and $3.4 \%$ for $\delta^{13} \mathrm{C}$ and $\delta^{15} \mathrm{~N}$, respectively; Post 2002), $21.5 \%$ of spider $\mathrm{C}$ and $0.0 \%$ of spider $\mathrm{N}$ were derived from A. ligulata extrafloral nectar. The discrepancy between the $\mathrm{C}$ and $\mathrm{N}$ estimates may result from concentration dependence (Phillips and Koch 2002). Nectar is generally enriched in C relative to $\mathrm{N}$ (Baker and Baker 1982), so nectar should contribute more to a consumer's $\mathrm{C}$ content than its $\mathrm{N}$, if assimilation rates of the two elements are equal. In any case, $95 \%$ confidence intervals for the fractional contribution of nectar to the diet did not exclude zero (Table 2).

Spiders living on A. ligulata, hopbush, and dead acacias differed significantly in diet, as evidenced by stable-isotope ratios of both $\mathrm{C}$ and N (Fig. 2C; Pillai's trace $\left.0.65, F_{4,24}=2.86, P=0.045\right)$. Stable-isotope profiles differed most markedly between spiders living on A. ligulata and those on dead acacia (contrast, $F=$ 9.82, $P=0.004$ ). Spiders on hopbush (a species lacking extrafloral nectaries) had an intermediate stable-isotope profile, which was not statistically distinguishable from that of spiders on A. ligulata $(F=2.81, P=0.103)$ or on dead acacia $(F=2.27, P=0.149)$.

\section{DISCUSSION}

Protection mutualisms, which are characterized by an exchange of resources (or shelter) in return for protection from predators, parasites, or competitors, are widespread in both terrestrial and marine communities. Examples include ant-plant, crab-coral, and endophyte-grass associations (reviewed in Bronstein [1998] and in Stachowicz [2001]). Because these mutualisms can affect the population dynamics of foundational species on which communities are assembled (e.g., plants and corals), they are important determinants of the structure and diversity of communities (Stachowicz 2001). This study enlarges the scope of this class of

TABLe 2. Analysis (via stable-isotope ratios) of the diet of Phryganoporus candidus spiders living on Acacia ligulata.

\begin{tabular}{|c|c|c|c|c|c|}
\hline \multirow[b]{2}{*}{ Element } & \multirow{2}{*}{$\begin{array}{c}\text { Trophic } \\
\text { fractionation } \\
\text { value }(\% o)\end{array}$} & \multicolumn{2}{|c|}{ From nectar } & \multicolumn{2}{|c|}{ From insects } \\
\hline & & Percentage & $95 \% \mathrm{CI}$ & Percentage & $95 \% \mathrm{CI}$ \\
\hline Carbon & $\begin{array}{l}0.0 \\
0.4 \dagger \\
1.0\end{array}$ & $\begin{array}{l}11.8 \\
21.5 \\
36.1\end{array}$ & $\begin{array}{l}0.0,38.5 \\
0.0,48.1 \\
8.0,64.0\end{array}$ & $\begin{array}{l}88.2 \\
78.5 \\
63.9\end{array}$ & $\begin{array}{l}61.5,100.0 \\
51.9,100.0 \\
36.3,91.6\end{array}$ \\
\hline Nitrogen & $\begin{array}{l}3.0 \\
3.4 \dagger \\
4.0 \\
5.0\end{array}$ & $\begin{array}{l}0.0 \\
0.0 \\
0.0 \\
9.6\end{array}$ & $\begin{array}{l}0.0,17.0 \\
0.0,23.0 \\
0.0,32.1 \\
0.0,47.7\end{array}$ & $\begin{array}{r}100.0 \\
100.0 \\
100.0 \\
90.4\end{array}$ & $\begin{array}{l}83.0,100.0 \\
77.0,100.0 \\
67.9,100.0 \\
52.3,100.0\end{array}$ \\
\hline
\end{tabular}

Notes: Estimates are given of the percentages of spider tissue $\mathrm{C}$ and $\mathrm{N}$ derived from two sources: extrafloral nectar and insect prey. Average $\delta^{13} \mathrm{C}$ values $( \pm 1 \mathrm{SE})$ were $-29.1( \pm 0.8)$, $-25.0( \pm 0.3)$, and $-25.5( \pm 0.4)$ for A. ligulata, insect prey, and P. candidus, respectively.

For $\delta^{15} \mathrm{~N}$, average values were $-0.5( \pm 0.3), 4.6( \pm 0.6)$, and $9.1( \pm 0.6)$, respectively.

$\dagger$ Mean trophic fractionation values from the literature (Post 2002). 


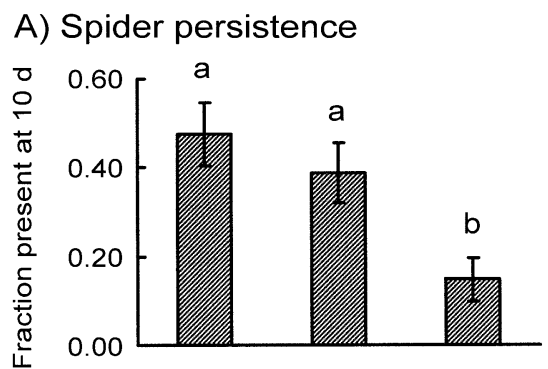

\section{B) Prey capture rates}

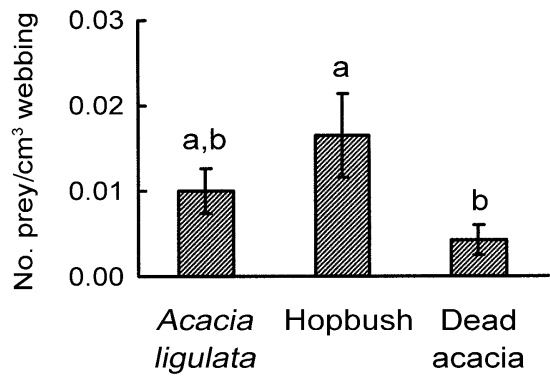

Plant host

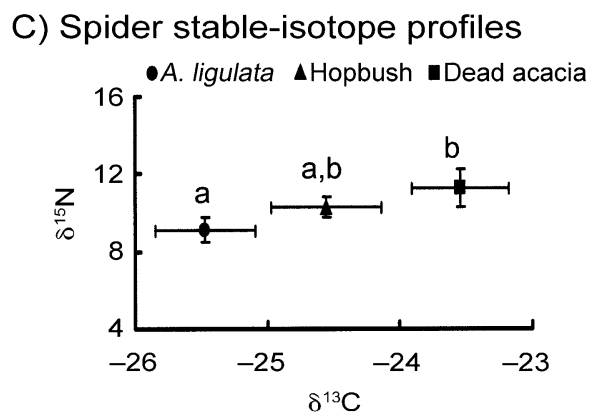

FIG. 2. Phryganoporus candidus responses to three common host plants at Menindee. Data are means \pm 1 SE. (A) Spider persistence in a 10-day experimental field trial. (B) Prey-capture rates in a 10-day experimental field trial. (C) Stable-isotope profiles $\left(\delta^{13} \mathrm{C}\right.$ and $\delta^{15} \mathrm{~N}$ values $)$ for $P$. candidus spiders collected from Acacia ligulata ( $n=6$ spiders), Dodonaea viscosa ( $n=5$ spiders), and dead acacia $(n=4$ spiders). Different lowercase letters indicate significant differences among hosts at $P<0.05$.

mutualisms by demonstrating mutualism between plants and a novel group of protectors-spiders.

\section{Benefits to plants}

In the Acacia ligulata-Phryganoporus candidus relationship, spiders cause $20-406 \%$ increases in viable seed production in localized areas within plants, via reductions in seed predation by heteropterans, wasps, and (in the observational study) weevils. Reduced predation could result from consumption of seed predators by the spiders (a density-mediated effect, Abrams et al. 1996); indeed corpses of the major seed-predator taxa have been observed in $P$. candidus webs. In addition, spider colonies are conspicuous and could cause seed predators to avoid areas within plants or even entire plants (a trait-mediated effect).

Spider-colony size was small relative to plant size, so average benefits to whole-plant seed production were modest, ranging from 0.38 to $5.77 \%$. However, the temporal pattern of benefits suggests that spiders may buffer A. ligulata against female reproductive failure, and thus may have larger beneficial effects on plant fitness than is suggested by mean values. In some years certain plants produced seeds only within spider nests. Furthermore, at each site, the year of lowest seed production per plant was associated with the greatest benefit provided by spiders. This pattern is possible only if the correlation between seed production and spider density is negative or zero, and indeed mean seed production (estimated as if spiders were absent) and mean colony density were uncorrelated across two sites and three years ( $r=-0.26, P=0.62, n=6$ observations). If increased attack by natural enemies is viewed as a form of stress for plants, then spider effects on A. ligulata may constitute an example of buffering against stress, an important class of benefits in mutualisms and commensalisms (Stachowicz 2001).

Costs imposed by spiders on A. ligulata plants were not measured, but could arise if $P$. candidus webs affect seed dispersal and/or photosynthesis. Future examination of the balance between benefits and costs in the A. ligulata-P. candidus system is critical to predicting constraints on coevolution in this system.

\section{Benefits to spiders}

Both experimental and observational studies suggested that $P$. candidus colonies perform better on live host plants compared with dead ones. Experimental colonies persisted longer on A. ligulata and hopbush than on dead acacias ("null" hosts that provide structural support but little else). Natural patterns of spider abundance suggest that geographic variation in host suitability exists; at Menindee, colonies were both largest and most abundant on A. ligulata, while at Cawndilla, colonies were most abundant on hopbush and colony size did not differ between the live hosts. Dead acacias appeared to be uniformly poor hosts.

Variation in $P$. candidus performance across hosts may reflect host differences in the availability and quality of microclimates, extrafloral nectar, or insect prey. Acacia ligulata appears to provide the densest shade of the alternate hosts examined (personal observation). This architectural feature may mitigate the threat of desiccation and thermal constraints on foraging time, important factors for spiders generally (Riechert and Harp 1987, Wise 1993). Acacia ligulata was also the only host providing extrafloral nectar. While it remains unclear whether A. ligulata nectar is a significant carbon source for $P$. candidus, water contained in the nectar could be utilized by the spiders to avoid desiccation. Finally, both the availability and quality of insect prey differed among hosts and likely have a large impact on 
spider performance. Prey-capture rates were substantially higher on A. ligulata and hopbush than on dead acacias, and stable-isotope signatures indicated that the elemental composition of prey consumed varied across hosts. Thus, $P$. candidus has the opportunity to maximize benefits from plants by colonizing hosts that attract high densities of preferred prey. Such variation among hosts is expected; plant species are known to differ in the numbers, body sizes, and/or chemical composition of insect visitors, resulting in variation in the behavior and hunting success of resident spiders (Gillespie and Tabashnik 1994, Morse 1999, Theodoratus and Bowers 1999, Schmalhofer 2001).

\section{Plant-spider mutualisms}

This study demonstrates that reciprocal, positive interactions between spiders and plants do indeed exist, adding to a short list of mutualisms involving spiders (Elgar 1993). Why are there so few documented examples of plant-spider mutualisms? One possibility is that the generalized diet of spiders may reduce their effectiveness as plant mutualists. Spiders can feed on species in the third trophic level; such intraguild predation can positively affect herbivores (e.g., Finke and Denno 2002) and harm plants (e.g., Gastreich 1999). Spiders may also prey on or interfere with pollinators (Louda 1982, Ott et al. 1998) as well as herbivores. Thus, the benefits spiders provide to plants may be routinely outweighed by costs.

Alternatively, it may be that a large fraction of plantspider relationships can be mutualistic, but have variable outcomes, making detection of mutualism difficult. As data from the A. ligulata-P. candidus system show, benefits to both parties are variable across time and space, and can be influenced by the phenology and/ or density of the partner, abiotic factors affecting seed production, and densities of third parties (e.g., herbivores). Such variability is key to understanding the ecological and evolutionary trajectories of facultative mutualisms (Bronstein 1994, Thompson 1999, Bronstein and Barbosa 2002).

\section{ACKNOWLEDGMENTS}

For support and help of many kinds, thanks to T. Auld, R. Taylor, J. Bean, A. Denham, and M. Ooi of the NSW National Parks \& Wildlife Service. Lodging and research facilities were generously provided by NSW NPWS. For long hot days in the field, seed counting, and spider wrangling, I am grateful to I. Baird, E. Bjerre, J. Chranowski, M. Cooper, C. Donnelly, S. Enning, B. Fisher, C. Griffin, L. Grosche, B. Henshaw, K. Herman, M. Judd, S. Lee, E. Lindsay, A. McDonald, R. McIntyre, C. Menke, J. Nolte, P. Rymer, N. Wurzburger, K. Yee and M. Zeppel. Many thanks to G. Cassis, C. Griswold, S. Heydon, R. Oberprieler, C. Reid, and H. Smith for spider and insect identification, to M. Stanton and J. Rudgers for advice and help, and to D. Phillips for advice on analyzing stable-isotope data. The comments of J. Bronstein, J. Rudgers, T. Smith, D. Spiller, J. Stachowicz, M. Stanton, S. Strauss, and two anonymous reviewers substantially improved the manuscript. This work was supported by an EPA STAR Fellowship and the Center for Population Biology (UC Davis).

\section{Literature Cited}

Abrams, P., B. A. Menge, G. G. Mittelbach, D. Spiller, and P. Yodzis. 1996. The role of indirect effects in food webs. Pages 371-395 in G. A. Polis and K. O. Winemiller, editors. Food webs: integration of patterns and dynamics. Chapman and Hall, New York, New York, USA.

Baker, H. G., and I. Baker. 1982. Chemical constituents of nectar in relation to pollination mechanisms and phylogeny. Pages 131-171 in M. Nitecki, editor. Biochemical aspects of evolutionary biology. University of Chicago Press, Chicago, Illinois, USA.

Bronstein, J. L. 1994. Conditional outcomes in mutualistic interactions. Trends in Ecology and Evolution 9:214-217.

Bronstein, J. L. 1998. The contribution of ant-plant protection studies to our understanding of mutualism. Biotropica 30:150-161.

Bronstein, J. L., and P. Barbosa. 2002. Multi-trophic/multispecies mutualistic interactions: the role of non-mutualists in shaping and mediating mutualisms. Pages 44-65 in T. Tscharntke and B. Hawkins, editors. Multitrophic level interactions. Cambridge University Press, Cambridge, UK.

Conover, W. J., and R. L. Iman. 1981. Rank transformations as a bridge between parametric and nonparametric statistics. The American Statistician 35:124-132.

Denno, R. F., C. Gratton, M. A. Peterson, G. A. Langellotto, D. L. Finke, and A. F. Huberty. 2002. Bottom-up forces mediate natural-enemy impact in a phytophagous insect community. Ecology 83:1443-1458.

Downes, M. F. 1993. The life history of Badumna candida (Araneae: Amaurobioidea). Australian Journal of Zoology 41:441-466.

Downes, M. F. 1994. The nest of the social spider Phryganoporus candidus (Araneae: Desidae): structure, annual growth cycle and host plant relationships. Australian Journal of Zoology 42:237-259.

Elgar, M. A. 1993. Inter-specific associations involving spiders: kleptoparasitism, mimicry, and mutualism. Memoirs of the Queensland Museum 33:411-430.

Finke, D. L., and R. F. Denno. 2002. Intraguild predation diminished in complex-structured vegetation: implications for prey suppression. Ecology 83:643-652.

Gastreich, K. R. 1999. Trait-mediated indirect effects of a theridiid spider on an ant-plant mutualism. Ecology 80: 1066-1070.

Gillespie, R. G., and B. E. Tabashnik. 1994. Foraging behavior of the Hawaiian happy face spider (Araneae: Theridiidae). Annals of the Entomological Society of America 87:815-822.

Gray, M. R. 2002. The taxonomy and distribution of the spider genus Phryganoporus Simon (Aranae: Amaurobioidea: Desidae). Records of the Australian Museum 54:275292.

Halaj, J., and D. H. Wise. 2001. Terrestrial trophic cascades: how much do they trickle? American Naturalist 157:262281.

Jackson, R. R., S. D. Pollard, X. J. Nelson, G. B. Edwards, and A. T. Barrion. 2001. Jumping spiders (Araneae: Salticidae) that feed on nectar. Journal of Zoology (London) 255:25-29.

Louda, S. M. 1982. Inflorescence spiders: a cost/benefit analysis for the host plant, Haplopappus venetus Blake (Asteraceae). Oecologia 55:185-191.

Maslin, B. R., and S. D. Hopper. 1982. Phytogeography of Acacia (Leguminosae: Mimosoideae) in Central Australia. Pages 301-315 in W. R. Barker and P. J. M. Greenslade, editors. Evolution of the flora and fauna of arid Australia. Peacock Publications, Frewville, South Australia.

Morse, D. H. 1999. Choice of hunting site as a consequence of experience in late-instar crab spiders. Oecologia 120: 252-257. 
Ott, J. R., J. A. Nelson, and T. Caillouet. 1998. The effect of spider-mediated flower alteration on seed production in golden-eye phlox. Southwestern Naturalist 43:430-436.

Phillips, D. L., and J. W. Gregg. 2001. Uncertainty in source partitioning using stable isotopes. Oecologia 127:171-179.

Phillips, D. L., and P. L. Koch. 2002. Incorporating concentration dependence in stable isotope mixing models. Oecologia 130: $114-125$.

Polis, G. A., and S. D. Hurd. 1996. Allochthonous input across habitats, subsidized consumers, and apparent trophic cascades: examples from the ocean-land interface. Pages 275-285 in G. A. Polis and K. O. Winemiller, editors. Food webs: integration of patterns and dynamics. Chapman and Hall, New York, New York, USA.

Post, D. M. 2002. Using stable isotopes to estimate trophic position: models, methods, and assumptions. Ecology 83: 703-718.

Riechert, S. E., and J. M. Harp. 1987. Nutritional ecology of spiders. Pages 645-672 in F. Slansky and J. G. Rodriguez, editors. Nutritional ecology of insects, mites, spiders, and related invertebrates. John Wiley and Sons, New York, New York, USA.

Riechert, S. E., and C. R. Tracy. 1975. Thermal balance and prey availability: bases for a model relating web-site characteristics to spider reproductive success. Ecology 56:265284.

Ruhren, S., and S. N. Handel. 1999. Jumping spiders (Salticidae) enhance seed production in a plant with extrafloral nectaries. Oecologia 119:227-230.

SAS Institute. 2000. The SAS system for Windows, version 8.1. SAS Institute, Cary, North Carolina, USA.

Scheiner, S. M. 2001. MANOVA: multiple response variables and multispecies interactions. Pages 99-115 in S. M. Schei- ner and J. Gurevitch, editors. Design and analysis of ecological experiments. Oxford University Press, Oxford, UK. Schmalhofer, V. R. 2001. Tritrophic interactions in a pollination system: impacts of species composition and size of flower patches on the hunting success of a flower-dwelling spider. Oecologia 129:292-303.

Schmitz, O. J., P. A. Hamback, and A. P. Beckerman. 2000. Trophic cascades in terrestrial systems: a review of the effects of carnivore removals on plants. American Naturalist 155:141-153.

Spiller, D. A., and T. W. Schoener. 1994. Effects of top and intermediate predators in a terrestrial food web. Ecology 75:182-196.

Stachowicz, J. J. 2001. Mutualism, facilitation, and the structure of ecological communities. BioScience 51:235-246.

Taylor, R. M., and W. A. Foster. 1996. Spider nectarivory. American Entomologist 42:82-86.

Theodoratus, D. H., and M. D. Bowers. 1999. Effects of sequestered iridoid glycosides on prey choice of the prairie wolf spider Lycosa carolinensis. Journal of Chemical Ecology 25:283-295.

Thompson, J. N. 1999. Specific hypotheses on the geographic mosaic of coevolution. American Naturalist 153:S1-S14.

Vogelei, A., and R. Greissl. 1989. Survival strategies of the crab spider Thomisus onustus Walckenaer 1806 (Chelicerata, Arachnida, Thomisidae). Oecologia 80:513-515.

Whitney, K. D. 2002. Dispersal for distance? Acacia ligulata seeds and meat ants Iridomyrmex viridiaeneus. Austral Ecology 27:589-595.

Whitney, K. D., and M. L. Stanton. 2004. Insect seed predators as novel agents of selection on fruit color. Ecology, in press.

Wise, D. H. 1993. Spiders in ecological webs. Cambridge University Press, Cambridge, U.K.

\section{APPENDIX A}

Background on stable isotopes and details of the sampling methods used in this study are available in ESA's Electronic Data Archive: Ecological Archives E085-045-A1.

\section{APPENDIX B}

Summary data on the effects of Phryganoporus candidus colonies on seed damage by heteropterans, weevils, and wasps are available in ESA's Electronic Data Archive: Ecological Archives E085-045-A2. 